\title{
ENSINO À DISTÂNCIA NA ENGENHARIA: CONTORNOS E PERSPECTIVAS
}

\author{
Antonio Galvão Novaes \\ Departamento de Engenharia de Produção e Sistemas \\ Universidade Federal de Santa Catarina \\ Caixa Postal 476, CEP 88010-970 - Florianópolis, SC \\ Tel: (0482) 32-0409
}

Os programas de pós-graduação em engenharia têm formado, no país, quantidade apreciável de mestrês nos últimos anos. Parcela muito pequena desses, no entanto, tem sido constituída por empregados de empresas que efetivamente os tenham enviado à Universidade para a obtenção de títulos pós-graduados. Por outro lado, em razão da recessão por que passamos, muitos dos candidatos a programas de mestrado em engenharia são jovens que não conseguiram emprego na indústria. Muitos desses jovens continuarão rondando as universidades e os órgãos de fomento, tentando prosseguir seus estudos (doutorado), pleiteando uma bolsa no exterior, etc.

Na América do Norte e na Europa tem-se lançado mão, em larga escala, do ensino à distância de nível superior, visando suprir as necessidades do sistema produtivo e da sociedade. Neste artigo discutem-se os aspectos conceituais e técnicos ligados ao ensino à distância na Europa e na América do Norte, apresentando-se uma bibliografia atualizada sobre a questão. Em seguida é feita uma análise das perspectivas e condições para sua implantação no Brasil.

Palavras-chaves: ensino à distância, ensino pós-graduado, ensino da engenharia

\section{Introdução}

O ensino à distância vem sendo utilizado no mundo inteiro há décadas, visando objetivos diversos e atingindo um público-alvo bastante expressivo. Porque o mesmo não ocorre no Brasil? Seriam nossas características sócio-culturais tão diversas das de outros povos a ponto de não se recomendar esse tipo de ensino? Acreditamos que a resposta não é essa e procuraremos mostrar como o ensino à distância pode realmente ajudar a retomada do desenvolvimento tecnológico em nosso país. Para isso é necessário ter uma idéia bastante clara das limitações, restrições e dificuldades a serem enfrentadas, sendo também necessário um projeto bem estruturado e, finalmente, muita vontade política de forma a garantir-se a consistência e a continuidade do projeto ao longo do tempo.

Neste artigo faremos uma análise geral sobre o ensino à distância em diversos países e regiões do Globo visando entender seus contornos e limitações, e procurando, 
assim, tirar eventuais lições aplicáveis à nossa realidade. Em seguida, analisaremos a situação brasileira, buscando uma formulação básica para o problema, em que: forma, conteúdo e resultados práticos fiquem devidamente equilibrados e adequados à nossa realidade.

Finalmente discutiremos as possibilidades de implantação do ensino à distância no Brasil, visando prioritariamente o aprimoramento da mão-de-obra de nível superior que atua diretamente na indústria, assunto que é de grande relevância para nosso desenvolvimento tecnológico. Secundariamente, uma vez implementado, tal sistema poderá ser também utilizado noutras atividades, beneficiando-se, assim, da capacidade instalada disponível. Uma bibliografia atualizada sobre o assunto é também apresentada, servindo de referência básica para os que se iniciam no estudo da questão.

\section{O Ensino à Distância na América do Norte}

É sabido que o ensino à distância é extensivamente utilizado na Europa e na América do Norte. Noutras regiões do globo o ensino à distância é também bastante empregado, como na Índia, em Hong Kong, na Austrália, na Nova Zelândia, na África e até mesmo no Caribe (KNAPPER, 1990).

De uma forma geral as instituições que oferecem ensino à distância podem ser classificadas de acordo com o nível e conforme sua especialização. O primeiro grupo, predominante na América do Norte (Estados Unidos e Canadá), é constituido por Universidades que oferecem simultaneamente cursos convencionais no campus e os mesmos cursos (ou parte deles) na modalidade à distância. Na Austrália, em que vigorava esse esquema por intermédio dos departamentos das Universidades denominados Australian External Studies, está ocorrendo uma reorganização, caminhando para a criação de oito centros autônomos de ensino à distância, seguindo assim o estilo europeu (HARRY \& ISMAIL, 1991).

Tomemos como exemplo a Universidade de Waterloo, no Canadá, bastante conhecida internacionalmente por seus programas em Engenharia, Matemática e Ciência da Computação, e que mantém programas de ensino à distância há cerca de 24 anos (KNAPPER, 1990). São oferecidos 325 cursos para cerca de 18.000 alunos anualmente. No nível de graduação, cerca de $1 / 5$ dos alunos realizam seu curso na modalidade à distância. Os cursos oferecidos são principalmente em Artes e Humanidades (com especial focalização em Línguas Estrangeiras), mas também com ofertas substanciais em Ciências e Matemática. Mais recentemente, em colaboração com a Lakehead University, estão oferecendo cursos em Environment Impact Assesment, Turismo e Recreation Resources Management. Normalmente todo curso que é oferecido na modalidade à distância é oferecido também no campus, quase sempre ministrado pelo mesmo professor.

O aluno típico de ensino à distância em Waterloo é do sexo feminino (56\% do total), com idade na faixa 30-40 anos, casada e com filhos (67\%), trabalhando fora (79\%), com bom nível de escolaridade e aplicando em média 8,5 horas por semana de seu tempo ao estudo. Apesar de inicialmente os programas de ensino à distância no Canadá terem visado indivíduos situados em regiões distantes, no meio rural, hoje a 
maioria vive dentro de um raio de $32 \mathrm{~km}$ de uma universidade. Do total, 53\% objetivam um diploma universitário, 26\% estudam por interesse pessoal e $15 \%$ para aperfeiçoamento profissional. Cerca de $87 \%$ dos estudantes à distância declararam estar satisfeitos com o ensino.

O ensino à distância na Universidade de Waterloo é mais espaçado no tempo, compreendendo 3 períodos por ano, com períodos de 13 semanas. As formas de media utilizadas compreendem audio cassetes, videotapes, e material impresso (textos, notas de aula). Os cursos são revistos a cada quatro anos. A avaliação dos estudantes é feita mediante a aplicação de 4 a 6 séries de exercícios ou trabalhos, e mais um exame final representando pelo menos $40 \%$ da nota final, exame esse realizado em 114 centros espalhados por todo o país.

Alguns problemas são também assinalados. As desistências são relativamente elevadas, compreendendo cerca de $35 \%$ dos alunos matriculados, sendo difícil identificar as causas reais, apesar de esforços continuados de melhoria dos resultados. Não obstante, os estudantes que permanecem no programa até o fim apresentam desempenho tão bom como os que estudam no campus (KNAPPER, 1990). Outro problema refere-se à atitude e à necessidade de treinamento apropriado do corpo docente. Em instituições que operam com as duas modalidades de ensino (no campus e à distância), como em Waterloo, o corpo docente não é recrutado e avaliado por suas qualidades didáticas, muito menos relacionadas ao ensino à distância. No entanto as habilidades para desenvolver e lecionar cursos à distância podem ser substancialmente diversas daquelas necessárias para o ensino convencional (KNAPPER, 1990). E, na prática, pouco incentivo é dado às atividades diretamente ligadas ao ensino à distância, quando comparado ao reconhecimento usual das atividades de orientação de teses, desenvolvimento de pesquisas, publicação de trabalhos, etc.

O Canadá também lidera um programa de cooperação internacional voltado aos países do Commonwealth britânico, intitulado Commonwealth of Learning (COL), criado em 1987 e implementado em 1989 (COL, 1991). Seu objetivo é criar ou ampliar o acesso às oportunidades de aprendizado, especialmente nos países em desenvolvimento pertencentes ao grupo, por meio do ensino à distância e da aplicação de novas tecnologias de comunicação à educação. Um exemplo desse tipo de colaboração é o programa conjunto Universidade de Waterloo/ St. Vincent (Caribe), onde cerca de doze estudantes realizaram cursos à distância oferecidos por aquela universidade, sendo que alguns desistiram, dois já obtiveram o diploma de BA, com mais quatro dos inscritos em vias de graduação. A maioria dos estudantes são professores de primeiro e segundo grau, ou funcionários públicos.

Nos Estados Unidos, a University of South Florida é outro exemplo interessante. Por intermédio do The Florida Engineering Education Delivery System (FEEDS), as instituições daquele estado que oferecem programas de pós-graduação em Engenharia formam os "centros primários", de onde os cursos à distância são transmitidos. Outras universidades e instituições, bem como algumas empresas, formam os "centros cooperativos", oferecendo suas instalações e infra-estrutura para a operacionalização dos cursos. O objetivo é oferecer uma ligação efetiva entre os corpos docentes localizados nos diversos campi e os estudantes pós-graduados que 
trabalham em empresas situadas na Flórida, algumas delas de alta tecnologia. Esses cursos são também disponíveis para engenheiros atuando profissionalmente naquele estado.

O diploma oferecido aos que completam os requisitos do curso à distância é o mesmo recebido por aqueles que optam freqüentar o mesmo curso no campus. Da mesma forma, os requisitos para admissão e aprovação são os mesmos para as duas modalidades de ensino.

O sistema de ensino à distância de Engenharia na Flórida, em nível de pósgraduação, utiliza básicamente dois tipos de media. O primeiro esquema é formado por sistema de televisão ao vivo, com comunicação de áudio nos dois sentidos, em que os estudantes são obrigados a assistir as aulas em conjunto, nos diversos "centros cooperativos", garantindo assim a participação coletiva e um certo nível de interação entre eles. Somente em casos de doença ou de viagem a serviço a ausência é justificável. Esse tipo de transmissão está em operação desde 1983 na University of South Florida. A segunda modalidade, denominada instrução tutorial em vídeo ("tutored video instruction", TVI), utiliza videotapes previamente gravados no campus, que são apresentados nos locais afastados da Universidade responsável pelo curso.

Desde o início desse programa, cerca de 26.000 engenheiros, trabalhando em mais de 100 empresas de natureza diversa, matricularam-se. Esse tipo de aula é acompanhado por um indivíduo selecionado e aprovado pelo Des cursos, seja na primeira modalidade (transmissão ao vivo), seja na que utiliza fitas pré-gravadas. No ano acadêmico de 1991/92, que foi do outono do primeiro ano à primavera do segundo, mais de 4.000 engenheiros se matricularam no sistema de ensino pósgraduado de Engenharia, à distância, no estado da Flórida.

Outra importante universidade norte-americana, reconhecida internacionalmente no campo das Engenharias, é Virginia Tech, localizada em Blacksburg, no Estado da Virgínia, que mantém desde 1983 programas de ensino à distância em nível de pós-graduação. A idéia básica do programa de ensino à distância é disseminar a pós-graduação em engenharia para as diversas regiões da Virgínia visando, de um lado, atrair indústrias de alta tecnologia para a região e, de outro, aprimorar a capacitação dos atuais empregados nas empresas do estado, dando-lhes melhores condições de promoção em suas respectivas carreiras. No ano acadêmico de 1983-84, Virginia Tech transmitiu seis disciplinas de engenharia a partir de seu campus em Blacksburg, com os sinais de TV recebidos numa sala de aula localizada em Richmond. A transmissão incluía sinais unidirecionais de vídeo e sinais bidirecionais de som, estes últimos transmitidos através de uma rede telefônica dedicada. No ano seguinte o curso foi ampliado com a criação de classes avançadas na George Mason University, ao Norte de Virgínia, e na Old Dominium University, ao leste do estado. Nesse ano, 18 disciplinas foram transmitidas por essa modalidade.

Em 1986, com a introdução da transmissão por satélite, o sistema de ensino à distância passou a atingir cerca de 30 pontos diversos, situados na Virgínia e em alguns estados próximos, e incluindo indústrias além das tradicionais salas de aula em universidades. Entre as instituições não universitárias e empresas atingidas, citam-se a 
NASA, a IBM, a Mitre Corporation e o estaleiro Newport News. Desde seu início em 1983, até 1991 (último ano com dados disponíveis), Virginia Tech ministrou 140 disciplinas em seu programa de ensino à distância, num total de 7.673 estudantes matriculados, tendo ocupado 96 professores nos cursos.

\section{A Experiência Européia}

Ao contrário da América do Norte, onde o ensino à distância em nível superior é geralmente ministrado pelas mesmas universidades que oferecem cursos convencionais no campus, na Europa predomina uma segunda modalidade, com instituições autônomas especialmente criadas para tal mister. É o caso da Open University, localizada em Milton Keynes, na Grã-Bretanha, e que opera desde 1969; a Fern Universität, situada em Hagen, na Alémanha e criada em 1967; a Universidade Aberta, criada em Portugal em 1988; a UNED - Universidad Nacional de Educación a Distancia, iniciada em 1987 na Espanha, e a CUD (Consorzio per l'Università a Distanza) na Itália, criada em 1984, entre outras (QUINTINO, 1991).

De um lado, as instituições universitárias européias especializadas no ensino à distância vêm-se dedicando, como suas congêneres norte-americanas, ao ensino de nível superior, oferecendo diplomas nos diversos campos do conhecimento. Mas notase também um grande esforço no ensino de línguas, em função da integração européia e da conseqüente necessidade de comunicação entre os povos. Mas há um aspecto, a nosso ver muito importante para a realidade brasileira, e que voltaremos a discutir mais adiante quando focalizarmos o ensino à distância no Brasil. Trata-se de utilizar o ensino à distância como alavanca no processo produtivo, objetivando o aprimoramento da mão-de-obra e o treinamento em atividades tecnológicas de ponta (D'AZEVEDO, 1991). Segundo esse modo de ver, o problema não é mais restrito a cada país, mas passa a ser agora uma questão da Comunidade Européia no seu todo, objetivando a transferência de conhecimento e de tecnologia, e envolvendo redes transeuropéias de natureza diversa (D'AZEVEDO, 1991).

A Comunidade Européia pretende eliminar, ou pelo menos reduzir, as barreiras à livre movimentação de mercadorias, de serviços, de capital e de pessoas entre seus estados membros. Tal objetivo deve ser apoiado por meio da criação de redes intraeuropéias de vários tipos. Quatro delas são destacadas: transportes, telecomunicações, energia e treinamento (D'AZEVEDO, 1991). A inclusão das três primeiras parece óbvia, cabendo uma discussão mais aprofundada sobre a última.

As universidades européias de ponta estão sendo chamadas a participar de programas de educação continuada e de treinamento visando tornar a mão-de-obra européia mais competitiva, facilitando o estabelecimento de parcerias supranacionais e "joint ventures". Foram criados programas específicos, como COMETT, LINGUA e ERASMUS, para treinamento de mão-de-obra na Europa, visando principalmente pequenas e médias empresas (D'AZEVEDO, 1991). Constatou-se que a indústria, de um lado, é bastante competente no desenvolvimento de aplicações concretas e imediatas relacionadas com suas atividades produtivas. De outro lado, a presença do componente universitário traz ao processo a precisão da disciplina acadêmica e a 
metodologia analítica necessária para enfrentar realidades complexas e cambiantes. Inversamente, a indústria traz ao processo o seu reconhecido pragmatismo e sua visão nitidamente prática do treinamento (D'AZEVEDO, 1991). Assim, a co-participação universidade-empresa nesse processo tenderá a trazer resultados mais eficazes.

Um problema que ocorre na Europa, de forma geral, é de natureza demográfica, com redução significativa da mão-de-obra jovem. Assim, a renovação da força de trabalho nas próximas duas décadas ficará parcialmente prejudicada, sendo necessário atualizar e melhorar as qualificações da força de trabalho atual (COMISSION OF THE EUROPEAN COMMUNITIES (CCE), 1991). Da mesma forma, é oportuno o treinamento de mulheres que desejam voltar a participar da força de trabalho após alguns anos de dedicação ao lar. A Comissão aponta também para o fato de que, apesar do crescente nível de desemprego nos países europeus, há deficiências significantes de qualificações especializadas. Constata-se assim um aparente paradoxo, com um processo acelerado de "eliminação de empregos/criação de empregos", numa economia em fase de rápida transformação e modernização. De uma maneira geral os objetivos básicos da Comunidade Européia, com referência ao ensino à distância, são (CCE, 1991):

-elevar o nível de qualificação dos que ingressam na força de trabalho;

-atualizar e elevar o nível de qualificação da atual força de trabalho por meio da educação continuada e do treinamento;

-possibilitar a participação crescente, na força de trabalho, de grupos até então pouco representados;

-garantir um maior grau de sinergia entre educação, treinamento e atividade econômica, de forma a ampliar e melhorar a aplicação das qualificações profissionais e do conhecimento.

Em conseqüência, alguns esforços já estão sendo realizados. Por exemplo, ERASMUS é um programa de cooperação e mobilidade interuniversitária. Quando concebido, o programa visava possibilitar a $10 \%$ dos estudantes universitários europeus o estudo noutros países da Comunidade. O objetivo era dar uma dimensão européia ao estudante, embora de forma restrita. Um dos objetivos do ensino à distância é então o de possibilitar a extensão desse conceito aos $90 \%$ restantes. Além disso, o sistema possibilita a integração dos corpos docentes, permitindo também atingir adultos e estudantes em tempo parcial (C.C.E., 1991, ref. 8).

O programa LINGUA, por sua vez, dá suporte aos esforços individuais de treinamento dos estados membros no sentido de aumentar a competência linguística dos jovens e dos trabalhadores, nos seus vários níveis, em toda a Europa. Em particular, tal programa visa preparar os estudantes antes do período de estudos no estrangeiro, possibilitando o ensino das línguas menos utilizadas. O programa COMETT tem sido empregado para ministrar treinamento continuado em tecnologias avançadas. De acordo com o exposto anteriormente, o programa incorpora uma estratégia explícita visando o desenvolvimento de modelos de cooperação entre universidades e indústrias, no âmbito da Comunidade. Mencionamos também o programa FORCE, que visa complementar os esforços dos estados membros no treinamento vocacional, bem como contribuir para a criação de técnicas inovadoras 
para treinar trabalhadores adultos nas empresas. Há ainda outros programas específicos, tais como TEMPUS, DELTA, EUROTECNET, etc, descritos no mencionado documento (CCE, 1991).

O esforço europeu de melhoria da mão-de-obra se estende também aos chamados países periféricos da CEE (Portugal, Espanha, Itália e Grécia), que têm sido objeto de análises específicas, visando diminuir as diferenças sócio-econômicas existentes entre os estados membros. Nesses países as empresas pequenas e médias são responsáveis pela maior parte dos empregos oferecidos. Em Portugal, mais de $90 \%$ dos empregos são localizados nas empresas pequenas e médias, sendo provável que na Espanha e na Grécia ocorra situação semelhante (QUINTINO, 1991). Tais empresas estão geograficamente dispersas em todos os quatro países. Além disso, a grande maioria dessas empresas são muito pequenas, tendo dificuldade em ceder seu pessoal para os cursos de treinamento, principalmente quando o local da aula é relativamente distante do trabalho. Quintino aponta ainda, como dificuldades adicionais, as deficiências de escolaridade do público-alvo, as resistências à adoção de novas tecnologias, a falta de motivação dos usuários, as diferenças culturais até mesmo dentro de cada país, e as dúvidas quanto à relação benefício/custo do ensino à distância. No entanto, diversos resultados positivos são analisados por Quintino. Por exemplo, em Portugal e na Espanha existem, há aproximadamente 15 anos, cursos por correspondência em "Tecnologia da Qualidade", promovidos pelas Associações de Qualidade Industrial. Por outro lado, num esquema de cooperação entre um centro de treinamento português e outro belga, foi possível desenvolver curso em Gerenciamento da Qualidade utilizando técnicas modernas.

Dos quatro países analisados por Quintino, a Itália parece estar à frente no que diz respeito ao ensino e ao treinamento à distância. Diversos exemplos são mencionados, incluindo treinamento no setor de transportes, na área bancária (S.Paolo di Torino), na administração (Centro de Treinamento Profissional de Modena), em manutenção na indústria cerâmica (Centro de Treinamento Profissional de Sassuolo), etc. Esses exemplos são dignos de destaque, pois não há apoio financeiro governamental para tal tipo de ensino à distância, sendo seus custos cobertos por empresas como a Fiat e a Olivetti, alguns bancos, e por progamas da comunidade européia, tal como o COMETT.

A experiência européia nos parece de grande valia para o equacionamento do ensino à distância no Brasil porque, embora com realidades sócio-econômicas bastante diversas, a necessidade de alavancar o sistema produtivo, mediante treinamento e atualização da mão-de-obra, constitui um ponto comum aos dois cenários.

\section{Questões Conceituais}

Escassíssimo material bibliográfico sobre ensino à distância é disponível no Brasil, enquanto, no exterior, existem centros de pesquisa especializados, periódicos, livros, associações, cooperação internacional, etc. Entre os periódicos citamos o American Journal of Distance Education, Open Learning, Journal of Eductional 
Television, e Distance Education. Somente na lista bibliográfica (parcial) deste trabalho, são citados 18 livros recentes, diretamente ligados ao ensino à distância.

Centros de pesquisa em ensino à distância, como o International Centre for Distance Learning, ligado à Open University inglesa, entre outros, vêm estudando a questão de maneira extensiva e intensiva, considerando não somente os aspectos técnicos do ensino (media, preparação do material para os cursos, etc), como também realizando reflexões conceituais sobre a eficácia do processo, os problemas sócioeconômicos, questões ligadas ao conteúdo, impactos na sociedade e no processo produtivo, etc. Um banco de dados contém informações sobre literatura em educação à distância em língua inglesa, de todo o mundo. Uma publicação periódica, New Accessions, resume e comenta novos documentos da área, além de indicar os próximos congressos e seminários (HARRY \& ISMAIL, 1991).

Nos Estados Unidos da América do Norte há o Educational Resources Information Center (ERIC), pertencente ao U.S. Department of Education, especializado em questões de ensino de uma maneira geral, e que opera como uma "clearinghouse" da área, fornecendo cópias de documentos, artigos, etc, redigidos em língua inglesa. O American Center for the Study of Distance Education, com base na Pennsylvania State University, por outro lado, abriga literatura apreciável sobre o assunto e desenvolve pesquisas na área.

Citamos ainda a Open Learning Agency, no Canadá, a Indira Gandhi National Open University, na Índia, o Hong Kong Open Learning Institute, situado em Hong Kong, e o National Institute of Multimedia Education, no Japão.

Certamente toda a documentação disponível e em elaboração nesses centros especializados não veicula apenas dados factuais sobre a questão do ensino à distância. Ao contrário, muito se tem analisado e discutido sobre as implicações sociais e culturais dessa forma de educação e treinamento. Um dos problemas que têm gerado muita reflexão dos pesquisadores é o referente ao processo de aprendizado. Em que medida o ensino à distância favorece ou não o aprendizado por parte dos estudantes?

$\mathrm{O}$ aprendizado efetivo, envolvendo real compreensão daquilo que está sendo ensinado, requer que o estudante conceitue as idéias, focalizando pelo menos um aspecto do ambiente à sua volta (MORGAN, 1990; MARTON et al., 1984). Esse enfoque contrasta com formas mais convencionais de ensino em que o aprendizado é visto como a mera aquisição seqüencial de pedaços elementares de conhecimento ou de informação. Um dos desenvolvimentos mais importantes nessa área é devido a EVANS \& NATION (1989), que introduziram a idéia de "reflexão crítica" no ensino à distância. Esses autores argumentam que tal tipo de reflexão constitui o foco central do aprendizado, e definem:

"Reflexão crítica é o processo pelo qual os seres humanos usam suas potencialidades analíticas para avaliar elementos de suas próprias vidas em relação a um quadro explicativo externo (teorias). A reflexão crítica é a precursora da mudança porque, através do reconhecimento das possibilidades de intervenção humana, ela encoraja as pessoas a melhorarem suas condições de vida em seus próprios termos". (EVANS \& NATION, 1989). 
Outro autor, WILLIS (1993), afirma que o maior desafio enfrentado pelo educador na modalidade à distância é a criação de exemplos que sejam relevantes e atrativos para os estudantes.

Essa preocupação com o processo de aprendizado per se na educação à distância pode, entre outras coisas, ser vista como uma reação a um excesso de tecnicismo vigente no setor. Não há dúvida que a Tecnologia Educativa tem tido, e continuará a ter, considerável impacto no ensino à distância. O problema é que, para muitos, as técnicas de ensino à distância e seus contornos tecnológicos, constituem, por assim dizer, a panacéia que pode resolver todos os problemas educacionais. Seus seguidores fiéis acreditam que, qualquer que seja o assunto a ensinar, êles desenvolverão a técnica apropriada para lecioná-lo melhor e de forma mais efetiva (MORGAN, 1990). Em outras palavras, essa maneira de encarar a Tecnologia Educativa no ensino à distância é, na verdade, um enfoque racionalista, tecnocrático, em que a forma e a media utilizadas são colocadas como chave universal para 0 sucesso.

As críticas a esse tipo de enfoque, baseadas em constatações empíricas e reflexões teóricas, induziram outras iniciativas, também de cunho racionalista e igualmente apoiadas numa excessiva valorização das formas de transmissão. Uma delas enfatiza o conceito de "estruturas de conhecimento", segundo o qual os professores que desenvolvem os cursos devem dissecar o assunto de forma a explicitar a estrutura lógico-conceitual subjacente, apresentando o esqueleto subjacente para os estudantes. (MORGAN, 1990). Pouco resultado tem sido obtido com esse enfoque, em parte devido às dificuldades em definir de forma clara e satisfatória essas "estruturas de conhecimento" para a grande maioria dos tópicos lecionados.

Uma outra crítica que é feita às organizações ligadas à pesquisa e à operacionalização do ensino à distância é a preocupação exagerada com dados estatísticos como forma de avaliação dos resultados. Segundo MORGAN (1990), parece que os métodos de pesquisa de campo nessas instituições têm um "momentum organizacional" próprio e autônomo, independente das atividades de análise de conteúdo e de reflexão teórica sobre o assunto. Em parte tal atitude pode ser atribuída à dificuldade de se fazer uma avaliação mais científica dos impactos positivos e negativos do ensino à distância. Por exemplo, o ensino à distância não favorece muito o intercâmbio entre os estudantes e entre os alunos e os professores, pois aqueles desenvolvem suas atividades individualmente, de forma mais ou menos isolada. Mas seria isso sempre uma desvantagem?

$\mathrm{Na}$ realidade a experiência tem demonstrado que muitos dos estudantes à distância escolhem essa forma de estudo porque ela possibilita uma mescla de flexibilidade e de privacidade. Na prática são poucos os estudantes, na modalidade à distância, que se utilizam das oportunidades de encontrar pessoalmente os professores e outros estudantes no campus, nas ocasiões apropriadas (KNAPPER, 1990). Mas um fato incontestável é representado pelas elevadas taxas de desistência observadas (KNAPPER, 1990; MORGAN, 1990). Estudos mais aprofundados sobre as razões sociais, culturais, econômicas e pedagógicas que provocam esse tipo de comportamento, estão sendo desenvolvidos nos centros de pesquisa dos países mais 
adiantados. Em particular, o Student Research Centre, da Open University inglesa, tem se preocupado bastante com esse tipo de problema.

Os aspectos teóricos e conceituais ligados ao ensino à distância são fundamentais para o equacionamento correto da questão, para a definição da forma mais adequada de transmissão da informação, para a identificação do público alvo e para a escolha do sistema de avaliação do aprendizado. Seria obviamente impossível, além de pretencioso, analisar profunda e exaustivamente essa questão no presente documento. Nosso objetivo ao abordar resumidamente e de forma preliminar tais problemas é o de alertar para o perigo de se caminhar, sem maiores reflexões, para soluções mecanicistas, em que sejam priorizadas formulações tecnologicamente avançadas com a esperança de que, por si mesmas, venham a resolver o problema do ensino em nosso país.

\section{Aspectos Tecnológicos e Operacionais}

O ensino à distância, em seu início, era realizado através do sistema postal, com o material dos cursos encaminhado ao estudante via correio, utilizando-se do mesmo veículo para retornar os trabalhos e exercícios à instituição responsável pelo programa. Ainda hoje muitos cursos à distância são operacionalizados via correio. Em Portugal e na Espanha, por exemplo, há cerca de 15 anos são ministrados cursos por correspondência na área de tecnologia da qualidade, pela Associação Portuguesa para a Qualidade e pela Associación Española por la Calidad (QUINTINO, 1991). Tal meio possibilitou o ensino dessa matéria em todas as regiões de Portugal, tendo tido bastante receptividade. A primeira edição do curso (1000 cópias) esgotou-se rápidamente. $\mathrm{O}$ estudante tinha uma ano para completar o curso e fazer todos os exercícios. Cerca de 250 estudantes conseguiram o certificado de freqüência, dos quais 10 se submeteram ao exame final com aprovação. Esse curso por correspondência é dirigido a trabalhadores, inspetores, técnicos e artesãos (QUINTINO, 1991).

Nota-se um aspecto bastante comum em programas desse tipo: embora muitos indivíduos se interessem inicialmente pelo curso, nele se matriculando e o acompanhando, são relativamente poucos os que o completam, sendo ainda mais reduzido o número dos que se submetem aos exames finais, obtendo aprovação. Não se pode dizer que a media utilizada seja em si responsável por esse fato. No entanto é preciso dar muita atenção ao preparo do curso, à sua transmissão e recepção, ao envolvimento do aluno com a matéria lecionada, etc, de forma a garantir resultados mais eficazes. É interessante observar que, mesmo em instituições de reconhecida qualidade de ensino e larga experiência na educação à distância, há uma intensa preocupação com a escolha adequada da media, evitando busca de milagres tecnológicos de resultados fugazes. A Universidade de Waterloo, no Canadá, e já citada, é um exemplo típico.

Analisando o ensino à distância em Waterloo, KNAPPER (1990) toca no problema da qualidade e eficácia dessa modalidade. Reconhecendo que a questão da 
qualidade do ensino é um assunto complexo e polêmico, esse autor analisa a relação entre a sofisticação do material produzido para os cursos e de sua disseminação, de um lado, e a realização concreta do aprendizado, de outro. Não há dúvidas de que o conteúdo dos cursos deve ser relevante, preciso e atualizado. Mas é menos evidente a afirmação de que os estudantes aprendem mais a partir de cursos cuja preparação siga estritamente as receitas engendradas por especialistas em tecnologia educacional. Segundo Knapper, medias mais sofisticadas como televisão, multimedia, e-mail, etc podem ser motivadoras e eficazes na comunicação de idéias mais complexas. No entanto formas mais simples, como fitas de áudio e material impresso, oferecem maior flexibilidade, característica que é importante nesse tipo de ensino. Por exemplo, o estudante pode aproveitar seus deslocamentos diários no ônibus ou metrô para ler o material fornecido ou para escutar a fita num walkman. O autor também alerta para o fato de que a sofisticação exagerada pode levar a cursos excessivamente antissépticos, em que faltam o toque pessoal e o calor humano obtidos com a presença direta ou mesmo indireta de um professor.

Apesar da reputação de Waterloo como uma universidade inovadora em termos tecnológicos, Knapper ressalta um certo conservadorismo na abordagem do ensino à distância. Conforme mencionado anteriormente, a flexibilidade é um elemento muito importante na estratégia daquela instituição. Daí, nas palavras do mencionado autor, a relutância em abraçar tecnologias de ensino à distância que requeiram a presença dos estudantes num local específico, num momento definido, como é o caso de transmissão de televisão ao vivo, teleconferência áudio, etc. Recentemente passaram a utilizar videotapes apenas como elemento complementar ao material impresso e às fitas de áudio, e somente para comunicar conceitos que, para sua compreensão, requeiram imagens em movimento. Por outro lado, começaram recentemente a utilizar computadores no ensino à distância, mas somente após uma avaliação cuidadosa dos aspectos pedagógicos envolvidos. Dessa forma foi excluído o uso do computador como principal meio de instrução, mas aproveitaram-se suas características técnicooperacionais para suprir um dos pontos mais críticos do programa: a dificuldade de comunicação entre os estudantes e o professor, especialmente nas atividades relacionadas com a elaboração das tarefas individuais. Com o apoio da Toshiba, que forneceu equipamentos e recursos financeiros, montou-se um curso de introdução à computação em que, em adição às fitas de áudio e ao material escrito, cada estudante recebe um laptop emprestado, com o software apropriado para elaborar os exercícios do curso. Os resultados são passados via modem ao professor, cujos comentários são retornados ao aluno pela mesma via. O curso é hoje lecionado regularmente com cerca de 50 alunos matriculados em cada período.Planeja-se adotar em breve a mesma sistemática noutros cursos do programa de ensino à distância.

É importante notar nesse exemplo que a escolha da media a ser utilizada é uma decorrência do enfoque que se deseja dar ao curso, considerando o ambiente, os aspectos culturais, o público-alvo, o tipo de assunto a ser ensinado, etc, e não ao contrário, em que os meios de transmissão e de tratamento da informação passam a ser vistos como a chave mestra para o sucesso do programa de instrução à distância. 
FARR \& MUSCARELLA (1991) compararam três formas de instrução no ensino à distância de um curso de Psicologia, com as aulas sempre lecionadas pelo mesmo professor. No primeiro caso, um certo número de alunos assistiu à aula, à frente do professor, numa sala-estúdio de TV, no campus. A segunda versão era formada por uma classe à distância, com um sistema de TV de dupla comunicação (two-way video, em que o professor pode acompanhar também os estudantes situados no local remoto). Finalmente, a terceira modalidade envolvia comunicação de áudio simultânea entre os alunos e professores (audioteleconferencing), suplementada por fitas de vídeo previamente gravadas e distribuídas. O objetivo do experimento era analisar o grau de participação e de interação dos estudantes. Os resultados mostraram que a presença do professor, seja pessoalmemte, seja através da TV, aumenta a interação dos estudantes, ocorrendo maior número de perguntas e de intervenções . Na terceira alternativa (audiotele-conferencing), houve menor número de intervenções, sendo que a maioria dessas envolvia comentários e não perguntas. Nos outros dois casos ocorreu o contrário, em que as intervenções compreenderam quase que tão somente perguntas. Segundo as autoras, tais comentários se revelaram substancialmente superiores às questões, sugerindo um maior grau de entendimento do material lecionado na terceira modalidade. Vários fatores podem causar tal resultado, alguns ligados à forma de estudo (por exemplo, apreensão direta na aula versus repetição continuada da fita de video, em casa, para fixação de aspectos de mais difícil assimilação), ao tipo de aluno (voltado ao estudo individual, introspectivo, versus estudante mais social, que aprecia a troca de experiências com seus parceiros), etc. A conclusão a que chegaram é de que, apesar das indicações de que a media utilizada influi nos resultados, muitos outros fatores de cunho social e psicológico têm peso importante na questão, não sendo ainda plenamente entendidos. Esse mesmo tipo de questionamento é manifestado por pesquisadores da Open University inglesa (MORGAN 1990, KIRKWOOD, 1991).

Tendo em vista os rápidos avanços na computação e na transmissão de dados, muitos pesquisadores e técnicos vêm envidando esforços no sentido de maior utilização de técnicas de multimedia no ensino à distância. O ensino à distância no mundo vem utilizando formas diversas de media , desde material impresso contendo textos e figuras, passando por fitas (de áudio e de vídeo), e chegando, mais recentemente, ao uso do computador no processo educativo. Enquanto o material impresso e as fitas são elementos passivos, não permitindo a interação do estudante com eles, o computador dá condições para uso mais dinâmico, com o usário respondendo aos estímulos e questões à medida que o ensino vai se processando. Os sistemas interativos de multimedia combinam o poder de comunicação da televisão (som e imagem), com a flexibilidade e as possibilidades de atuação e controle do computador. Com esse sistema o estudante mergulha no aprendizado utilizando ao mesmo tempo suas capacidades visuais e auditivas, e executando atividades em interação constante com o sistema. Num relatório à Comissão das Comunidades Européias sobre perspectivas de uso de multimedia no ensino à distância na Europa, SHERWOOD-ROBERTS \& VERVEST (1991) avaliam hardware e software 
disponíveis, indicam as áreas onde tal sistema pode ser aplicado, e apresentam dois estudos de casos.

O objetivo básico do mencionado relatório é o aprimoramento da força de trabalho nos países membros da CEE, mediante treinamento à distância. Quatro áreas potenciais de aplicação são detectadas: (a) treinamento, no trabalho, em atividades técnicas; (b) treinamento, no trabalho, em atividades envolvendo relações interpessoais (vendas, relações com clientes, línguas); (c) cursos abertos, em que o treinamento é realizado fora do local de trabalho, visando o aprimoramento não diretamente ligado às atividades do dia-a-dia da empresa, mas com olhos no futuro; (d) treinamento dos instrutores e gerentes. Apesar de os mencionados autores se revelarem adeptos do uso de multimedia nesse tipo de ensino à distância, as necessárias ressalvas quanto ao caráter instrumental (e portanto acessório) da tecnologia são enfatizadas. Nas conclusões e recomendações alertam para que a escolha da tecnologia ou combinação de tecnologias mais adequadas seja sempre feita após uma criteriosa análise do tipo de treinamento a ser desenvolvido, do público-alvo a que se destina, e onde e quando será o sistema aplicado. Nenhuma tecnologia per se é a melhor, em termos absolutos, pois sua escolha é função de múltiplos fatores.

Muito se tem estudado, nos países mais adiantados, sobre aplicações de novas tecnologias ao ensino, em particular ao ensino à distância. Na Inglaterra, por exemplo, mais de 85\% dos estudantes da Open University possuem aparelho de video cassete em casa, levando-os a gravarem previamente os programas educativos para assistí-los em horário mais conveniente (KIRKWOOD, 1991a). Os aspectos sócio-culturais e a tradição já imposta ao sistema de ensino à distância condiciona, assim, a escolha das opções tecnológicas, principalmente nos países com longa e extensa experiência nesse setor. Já a multimedia, por sua vez, tem sido utilizada por grandes empresas visando tornar mais ágil o treinamento e diminuir seus custos. Por exemplo, a IBM, na Europa, utiliza 1.500 aparelhos de videodisco para dar apoio ao setor de vendas do IBM PC, bem como para treinamento de revendedores e de técnicos. O sistema opera com toque de tela e pode ser ligado a videotexto (SHERWOOD-ROBERTS \& VERVEST, 1991). Na Alémanha, a IBM utiliza o sistema de aprendizado LTS 90 em mais de 100 estações de treinamento, envolvendo tópicos de hardware e de software, tendo obtido uma redução de 36\% nos custos respectivos. O Lloyds Bank vem utilizando 1500 unidades que associam micro-computador com videodisco, para treinamento de pessoal, tendo reduzido o treinamento individual de 18 horas para cerca de 12 a 14 horas. A British Telecom, por outro lado, utilizando 200 estações interativas, reduziu o custo de treinamento por pessoa de 150 libras para 15 libras (SHERWOODROBERTS \& VERVEST, 1991).

\section{Possibilidades do Ensino à Distância no Brasil}

Diversos programas educativos e culturais têm sido transmitidos via rede convencional de televisão para todo o país, preparados por órgãos do Governo Federal e outros (TVs educativas estaduais, por exemplo). Uma característica comum em todos esses esforços é a ausência de interação entre estudantes e professores. As pessoas que 
assistem a tais progamas o fazem passivamente e não têm condições de fazer perguntas e interagir com os instrutores e com os demais estudantes. Pior do que isso, não existe nenhuma avaliação do desempenho dos estudantes, seja por meio de exercícios obrigatórios, seja por meio de exames ou de outra forma qualquer de controle dos resultados alcançados. Óbviamente, não há também qualquer controle de freqüência. Os programas são, por assim dizer, lançados ao ar, ficando por conta dos eventuais interessados a persistência no acompanhamento do curso (número de transmissões assistidas e tempo total de exposição à transmissão), estudo e revisão da matéria lecionada, elaboração de exercícios, etc. Não é de se estranhar, em função disso tudo, que os resultados práticos alcançados até agora, em que pesem os recursos humanos e financeiros aplicados, sejam tão medíocres.

Há também diversos cursos pagos, por correspondência, mantidos por organizações particulares, que cobrem áreas técnicas específicas (corte e costura, conserto de rádio e televisão, etc). $\mathrm{O}$ alcance de tais cursos é bastante restrito, e não são bem aceitas na sociedade e nas empresas as qualificações resultantes.

Tais experiências medíocres são talvez responsáveis pelo pouco interesse manifestado pelos órgãos governamentais, pelas universidades e pelas empresas em relação ao ensino à distância no Brasil. Muito embora esse assunto já tenha sido ventilado, em ocasiões diversas, nada de concreto ocorreu até agora. No entanto, pelo papel extremamente importante que o ensino à distância pode ter no desenvolvimento tecnológico e econômico do país, torna-se imperiosa a exorcização desses fantasmas, que pode ser conseguida mediante um projeto corretamente elaborado e implantado e, principalmente, mantido íntegro e coerente ao longo do tempo. Para isso é necessária vontade política, recursos e dedicação de seus executores, como também continuidade na sua aplicação.

As universidades brasileiras vêm sendo cobradas pela sociedade no sentido de um maior engajamento em relação aos problemas atuais do país, principalmente os de cunho social e econômico. Problemas crônicos de saúde, educação, moradia, transporte, estão cada vez mais sérios, exigindo soluções criativas e imediatas. Cobrase também uma maior aproximação da universidade em relação aos problemas das empresas. São vários os fatores que têm provocado esse distanciamento. O afastamento geográfico, sem ser o mais importante, é no entanto um fator que tem aumentado o distanciamento entre a universidade e as indústrias. Enquanto as melhores universidades estão localiza-das, na sua maioria, nos grandes centros urbanos do País, o parque industrial apresenta muitas empresas dispersas geograficamente. Isso obriga o deslocamento dos candida-tos à pós-graduação, com prejuizo de suas atividades profissionais no caso de estudo em tempo parcial, e acarretando custos apreciáveis de relocação e moradia no caso de participação em tempo integral. Tal fato reduz ainda mais as possibilidades de os empregados de empresas freqüentarem cursos de pós-graduação ou de extensão universitá-ria. No Estado de Santa Catarina essa situação é particulamente crítica, pois a única universidade pública com pós-graduação reconhecida e atividades de pesquisa de ponta, a UFSC, está situada em Florianópolis, enquanto as indústrias se localizam em municípios mais afastados, como Joinville, Blumenau, Jaraguá do Sul, etc. Uma forma utilizada pelo Departamento de Engenharia 
de Produção e Sistemas da UFSC para minorar esse tipo de limitação tem sido o atendimento da demanda mais remota mediante cursos de especialização ministrados "in loco". Seus professores passaram a lecionar cursos em vários pontos do País, começando por Santa Catarina (Joinville, Blumenau e Criciúma), mas estendendo o programa também a outros estados como, por exemplo, Rio Grande do Sul (Caxias do Sul, Santa Maria), Paraná (Curitiba, Londrina, Cascavel), Amazonas (Manaus), e Maranhão (São Luis).

A implantação do ensino à distância em algumas universidades brasileiras de ponta ajudará a reduzir as mencionadas limitações, melhorando decisivamente a integração entre o meio acadêmico e nosso parque industrial. Os pontos até aqui analisados mostram estarem maduras as condições para a implantação do ensino à distância no Brasil, seja na forma de cursos de especialização, voltados essencialmente para o aprimoramento e a atualização dos conhecimentos daqueles que atuam diretamente no setor produtivo, seja também na forma de outras modalidades, como o mestrado. Resumidamente, os fatores favoráveis à sua implantação no momento atual são:

(a) A qualificação de alguns cursos de pós-graduação em Engenharia, no País, que já atingiram um nível bastante satisfatório, estando atualizados em relação às recentes técnicas e metodologias disponíveis no exterior;

(b) A necessidade de a universidade participar mais diretamente na solução de problemas sociais e econômicos do país. Sob este aspecto a melhoria do nível de emprego, conseguida com a melhor colocação de nossos produtos no mercado interno e externo, fruto da capacitação de nosso parque industrial, e com a conseqüente alavancagem na economia, é um objetivo que pode ser atingido com o apoio da Universidade.

(c) O reduzido impacto dos atuais programas de mestrado e doutorado no país sobre o processo produtivo;

(d) A dispersão geográfica de grande número de indústrias em relação aos pontos de localização das universidades aptas a oferecer cursos de pós-graduação e de especialização atualizados e reconhecidos;

(e) A experiência já acumulada por alguns cursos universitários de ponta no oferecimento de cursos de especialização "in loco".

Ao contrário da Europa, onde a maior parte dos cursos à distância é oferecida por instituições específicamente criadas para tal, no Brasil deve-se sediá-los nas universidades com reconhecidos méritos nos campos de conhecimento específicos. Isso porque seria muito improvável conseguir níveis de qualificação compatíveis, numa conjuntura carente de recursos financeiros e de pessoal qualificado. E, deve-se ressaltar, um programa que objetive melhorar efetivamente as condições de competitividade de nosso parque industrial, não pode apenas tocar de leve nos problemas relevantes, numa abordagem superficial, mas precisa ir a fundo e atingir o âmago da questão, desenvol-vendo cursos bem estruturados e eficazes. Ou seja, não se deve focalizar o ensino à distância primordialmente sob a ótica das técnicas de tratamento da informação (vídeo, multimedia, etc), ou de sua transmissão, pois tais elementos são meramente instrumen-tais e ancilares a um prévio equacionamento da 
questão no terreno conceitual e programático. Parece ser tradição no Brasil enfrentar tais tipos de problema pelos seus aspectos acessórios, em lugar de aprofundar o conteúdo em primeiro lugar. Não são de estra-nhar, nessas condições, os desperdícios e os pífios resultados de tais empreitadas.

\section{Estrutura Básica do Curso}

Uma das áreas mais propícias para se iniciar o ensino à distância no país, com impacto imediato e benefícios significativos é a de Gestão da Qualidade e Produtividade, que se insere dentro da política brasileira de competitividade, consolidada pelo PBQP (Programa Brasileiro de Qualidade e Produtividade). Tal programa visa a criação e a consolidação de competência em gestão da qualidade, disseminando conceitos, metodologias, sistemas e técnicas apropriadas para empresas e organizações diversas, públicas e privadas. O oferecimento de curso à distância nessa área terá como objetivos principais a formação, o aperfeiçoamento e a capacitação de profissionais que atuam no planejamento, implantação, gestão e avaliação de sistemas de qualidade e produtividade empresarial. O programa, assim, estará voltado ao pessoal que, por força de suas atividades usuais ou pela motivação que o assunto desperta, necessita de informações conceituais básicas ou práticas sobre Qualidade e Produtividade, bem como sobre as técnicas usuais utilizadas, no tocante a processos e de produtos industriais. Com o sistema de ensino à distância a ser implantado objetivase inicialmente oferecer educação de qualidade a indivíduos de nível superior que estejam efetivamente engajados na indústria, sem que tenham que se deslocar para o local da universidade, o que representa normalmente um deslocamento desgastante e difícultoso.

Mas, para que sua implantação produza resultados positivos, é necessário garantir, desde logo, alguns requisistos fundamentais para seu sucesso e continuidade. Em primeiro lugar, não há como garantir o reconhecimento e a aceitação das qualificações resultantes de tal tipo de curso por parte da sociedade e das empresas se não houver um sistema de controle e avaliação rigoroso e eficaz. Nos cursos universitários convencionais é notória a dificuldade enfrentada pelos professores em exigir o cumprimento de prazos e a observância de um padrão de qualidade mínimo na elaboração das tarefas e exercícios, seja na graduação, seja na pós-graduação. Mesmo as provas e exames são enfrentados pelos estudantes após muitos resmungos e tentativas de adiamento, ou mesmo de sua substituição por outras formas de avaliação. Nota-se, por outro lado, um número crescente de casos de falsidade ideológica por parte de estudantes, com obtenção fraudulenta de questões, substituição de pessoas na execução das provas e exames, etc. Assim, é necessário estabelecer uma estrutura logística de suporte que garanta a lisura das avaliações e o cumprimento das obrigações. Isso será conseguido mediante a seleção e designação de pessoal capacitado nos locais remotos de recepção dos cursos, nos moldes vigentes na América do Norte e na Europa. Na Flórida, por exemplo, há um proctor em cada ponto de recepção dos cursos, que atua como representante da universidade e executa as atividades logísticas e de controle locais. 
Essa estrutura logística de apoio não se restringirá, no entanto, ao desempenho de funções de controle e de segurança. Haverá necessidade de se produzir, transportar, guardar e distribuir material impresso, videotapes, provas, exercícios para serem elaborados em casa, etc. Essa estrutura deve ser montada especificamente para o programa de ensino à distância e, obviamente, acarretará despesas de custeio permanentes.

Outro aspecto importante na definição da estrutura básica do curso à distância está ligado à forma de exposição do aluno ao meio de transmissão das informações. Embora algumas instituições estrangeiras estejam privilegiando formas de media mais flexíveis, tais como fitas de áudio ou vídeo pré-gravadas e distribuídas aos estudantes, e mesmo e-mail através de microcomputadores ligados em rede, consideramos muito importante a presença dos alunos na mesma sala e a transmissão ao vivo da aula a partir de um estúdio no campus. Esse direcionamento aparentemente estreito visa evitar um afastamento muito radical e súbito da forma de ensino hoje adotada universalmente em nossas universidades. Com o tempo, e a com a experiência acumulada devidamente respaldada por estudos pedagógicos e avaliações adequadas, será eventualmente possível mudar gradativamente o processo. Hoje, por exemplo, são poucos os estudantes prospectivos que dispõem de microcomputador em casa e que têm condições de adquirir um modem para ligá-lo à rede da universidade. Assim, um sistema de ensino à distância, que se apoiasse extensiva e intensivamente desde sua implantação, em técnicas de multimedia, resultaria inevitavelmente num modelo elitista e extrema-mente restrito. Nada impede, no entanto, que, com a evolução dos usos da informática e seu barateamento, se vá adaptando o sistema de ensino à distância ao longo do tempo, estendendo-o a outros tipos de media.

Um terceiro aspecto a considerar na implementação do curso à distância é o envolvimento efetivo das empresas no programa. Quando o número de estudantes o justificar, poderão ser instaladas salas de aula remotas em indústrias específicas, que arcarão com as despesas de instalação de equipamentos de som, de TV e de telefonia, bem como com os móveis e a proteção acústica necessários. Para que o empreendimento não fique restrito apenas às indústrias de grande porte, serão instaladas salas de aulas remotas em faculdades, escolas ou outras instituições locais, que receberão interessados individuais e empregados das empresas da região.

São relacionados, a seguir, alguns pontos importantes referentes à organização e à forma de funcionamento do curso à distância em questão:

(a) Corpo Docente: basicamente seria o mesmo que atua hoje nos diversos cursos de especialização e de pós-graduação oferecidos no país. Sua seleção deve ser feita com base no conhecimento e na experiência demonstrados em atividades anteriores. Assessoria específica sobre técnicas educacionais atualizadas, aspectos pedagógicos, postura diante das câmeras de TV, etc também deverá ser suprida.

(b) Cumprimento dos Requisitos Escolares: os cursos à distância serão tratados como cursos normais da universidade e portanto, a obtenção de diploma de especialização, ou de Mestre, exigirá o cumprimento rigoroso das exigências do Regimento Geral de Pós-Graduação, Estatuto e normas gerais vigentes nas universidades. 
(c) Programas das Disciplinas: a elaboração dos programas das disciplinas e o seu respectivo ordenamento levará em conta a seqüência natural de exposição das matérias a serem lecionadas. Para melhores resultados, poderá ser definido um programa de nivelamento básico para os estudantes, visando eliminar ou reduzir desigualdades mais significativas entre os indivíduos.

(d) Avaliações: os estudantes serão submetidos a um processo de avaliação que envolverá testes, resolução de exercícios, provas, exames e análise de casos, e que determinará, em última instância, o grau de aproveitamento de cada disciplina. Tais avaliações ocorrerão no local onde o estudante assiste às aulas, não havendo assim necessidade de deslocamentos interurbanos para realizá-las.

(e) Contacto com o Professor: o contacto com o professor da disciplina será estimulado e se realizará de três formas diferentes:

(i) As salas remotas serão dotadas de telefones diretamente ligados ao estúdio situado no campus, de onde a aula estará sendo transmitida. O aluno fará sua pergunta, quando necessário, via telefone. A pergunta será ouvida pelo professor e pelos estudantes no estúdio central, podendo então ser imediatamente respondida e discutida;

(ii) Em horários específicos de atendimento o professor estaria disponível para atendimento aos alunos, através do telefone;

(iii) Durante o período escolar, numa data previamente agendada, o professor se reuniria pessoalmente com os estudantes de um determinado município, num encontro social, permitindo maior entrelaçamento entre docentes e discentes, bem como possibilitando maior aproximação do professor com as empresas e órgãos patrocinadores locais.

(f) Local de Transmissão da Aula: o professor apresentará sua aula, na hora e dia aprazados, diante de um grupo de estudantes, num estúdio especialmente montado para tal no campus universitário. Esse estúdio contará com todos os equipamentos necessários, tais como câmeras de vídeo, instalação de som, proteção acústica, retroprojetores, etc. Os estudantes que vão assistir às aulas no campus serão alunos regularmente matriculados na forma convencional, pois é importante que haja interação normal com o professor, com perguntas, discussões, etc. Isso ajudará a desinibir os estudantes localizados nas salas remotas e dará ao professor elementos importantes para o estabelecimento do ritmo do curso.

(g) Transmissão e Recepção do Sinal: tipicamente o sinal de TV é inicialmente enviado às instalações da Embratel. Essa empresa oferece um serviço, denominado "TV Executiva", que permite a transmissão, em circuito fechado, a partir de um ponto determinado, sendo o sinal recebido em várias localidades simultaneamente (máximo de 52 locais diferentes por vez). Canais adicionais de áudio e de comunicação de dados também podem ser utilizados. Deve-se notar que os sinais são devidamente codificados de forma a evitar seu uso por pessoas não autorizadas. Cada local de recepção será dotado de uma antena parabólica com decodificador.

(h) Material Suplementar: Além das as aulas assistidas em tempo real deverá ser elaborado e distribuido aos estudantes material suplementar variado, tal como 
textos impressos, videotapes contendo gravação das aulas ou informações adicionais (à base de empréstimo), livros (também à base de empréstimo), etc.

(i) Intercâmbio Universidade/Indústria: as salas de aula remotas deverão ser montadas de preferência em empresas ou em associações patronais. Se não for possível nenhuma dessas alternativas, as instalações poderão ser localizadas numa escola ou faculdade mas em estreito entendimento com as indústrias locais. Os profissionais que assistirem ao curso desenvolverão trabalhos e resolverão problemas e exercícios em assuntos de real interesse para as empresas. Em particular, os trabalhos de conclusão do Curso de Especialização deverão versar sobre tópicos aplicados, préviamente identificados pelo corpo docente, juntamente com os executivos das empresas envolvidas.

\section{Conclusões}

O programa de Ensino à Distância na Área de Gestão da Qualidade e Produtividade está para ser implantado na Universidade Federal de Santa Catarina, pelo Departamento de Engenharia de Produção e Sistemas. O Ministério de Educação, por intermédio da Secretaria de Ensino Superior, está empenhado em levar o projeto adiante, pois, uma vez implantado, a infraestrutura disponível e a experiência acumulada permitirão estendê-lo a outros projetos educativos.

Um grande número de empresas tem procurado a UFSC, manifestando interesse imediato no programa. Acreditamos que, bem apoiado e bem estruturado, essa iniciativa terá reais possibilidades de contribuir positivamente para a melhoria das condições educacionais em nosso país.

\section{Referências Bibliográficas:}

COMMISION OF THE EUROPEAN COMMUNITIES: Open and Distance Higher Education in the European Community. Report from the Commission of European Communities, SEC (91) 897 Final, 24 Maio 1991a.

COMISSION OF THE EUROPEAN COMMUNITIES: Open Distance Learning in the European Community. Memorandum. Report no. COM(91)388, 12 Nov. 1991, Bruxelas (Bélgica), 1991b.

COMMONWEALTH OF LEARNING : Canadian Distance Educators Meeting. Sudbury, Ontario (Canadá), 8-9 de Julho 1991. 
D'AZEVEDO, R. C.: Transeuropean Networks for Education and Training: Towards Systems and Services for Effective Educational Networking in the European Community. Seminar on Trans European Networking of Universities in Continuing Engineering Education, Leuven (Bélgica), 28/29 Novembro, 1991.

EVANS, T. \& NATION, D.: Critical Reflections on Distance Education. Falmer Press, Lewes (UK), 1989.

FARR, C.W. \& MUSCARELLA. D.: Is Video Really Necessary? A Study Comparing Interactivity in Video and Audio Classrooms. report ED 350 984, U.S. Department of Education, Office of Educational Research and Improvement, Educational Resources Information Center (ERIC). 1991.

HARRY, K. \& ISMAIL, N.: "Information Work in Distance Education: International Perspectives". 4th Meeting, Proceedings of the Asian Association of Open Universities, Colombo (Sri Lanka), 18-19 Setembro, 1991.

HOLMBERG, B.: Perspectives of Research on Distance Education. (Survey Report), Zentrales Institut für Fernstudienforschung, Fern Universität, Hagen (Alemanha), 1988.

HOLMBERG, B.: Status and Trends of Distance Education. Kogan Page, Londres (U.K), 1981.

HOLMBERG, B.: The Growth and Structure of Distance Education. Croom Helm, Beckenham (U.K), 1986.

KIRKWOOD, A.: "Into the Video Age: Open University Television in the 1990's", Journal of Educational Television, Vol. 16, no. 2, pp. 77-85, 1990.

KIRKWOOD, A.: The Present and the Future of Audio-Visual Production Centrês in Distance Universities. trabalho apresentado em Conference on Audio Visual Media and New Technologies at the Service of Distance Education, Madrid (Espanha), Maio 1991a.

KIRKWOOD, A.: The Demands of an Information-conscious Society on a National Distance Teaching University. trabalho apresentado na Conference on Audio Visual Media and New Technologies at the Service of Distance Education, Madrid (Espanha), Maio $1991 \mathrm{~b}$.

KNAPPER, C.: Audio-Teleconferencing in Distance Education: The Waterloo

Experience. Commonwealth of Learning Conference on the Future of Distance Education, Kingston (Jamaica), 14-16 Julho 1990.

MARTON, F.; ENTWISTLE, N.; HOUNSELL, D. (eds.): The Experience of Learning. Scottish Academic Press, Edinburgh (U.K)., 1984.

MOORE, M.G. (eds.): Contemporary Issues in American Distance Education. Pergamon Press, Londres (U.K), 1990.

MORGAN, A.: "Qualitative Methodologies in Research in Distance Education". Distance Education, vol 5, no. 2, pp. 252-267, 1984.

MORGAN, A.: Whatever Happened to the Silent Scientific Revolution? Research, Theory and Practice in Distance Education. Relatório IET-R-35, Institute of Educational Technology, Open University, Inglaterra, 1990.

QUINTINO, L.: The Potential of Distance Education and Training for Small and Medium-Sized Enterprises in the Mediterranean Countries of the European 
Community , Relatório para a Commission of the European Communities, Task Force Human Resources, Education, Training, and Youth, Luxemburgo, Março 1991.

ROWNTREE, D.: Educational Technology and Curriculum Development. (2a Edição), Harper Row, Londres (U.K.), 1982.

RUMBLE, G.: Planning and Management of Distance Education. Croom Helm, Londres (U.K.), 1986.

SCHRUM, L.: Innovation and the Process of Change: A Case Study in Distance Education, Doctoral Dissertation, Universirty of Oregon, Eugene, 1991.

SCHRUM, L.: Information Age Innovations: A Case Study of Online Professional

Development, trabalho apresentado no Annual Conference of the American Educational Research Association, San Francisco, Califórnia, 20-24 Abril, 1992.

SEWART, D. \& DANIEL, J. (eds.): Developing Distance Education. International Centre for Distance Education, Oslo (Noruega), 1988.

SHERWOOD-ROBERTS, P. \& VERVEST, P.: Technology Options for Multimedia in Distance Education, relatório à Comissão das Comunidades Européia - Task Force Human Resources, Education, Training, and Youth, Luxemburgo, 1991.

UNESCO: Priority: Africa. Seminar on Distance Education, Arusha (Tanzânia), 24-28 Setembro 1990, Final Report , Paris, 1990.

WILLIS, B.: Distance Education: A Practical Guide, Educational Technology

Publications, Englewood Cliffs, N.Jersey (E.U.A)., 1993.

\section{Bibliografia Complementar:}

BAATH, J.A.: "Distance Student's Learning -- Empirical Findings and Theoretical Deliberations". Distance Education, Vol. 3, no. 1, pp. 6-27, 1982.

BATES, A.: "Television, Learning and Distance Education". Journal of Educational Television, Vol. 14, no. 3, pp 213-225, 1988.

BEARE, P.L.: "The Comparative Effectiveness of Videotape, Audiotape, and Telelecture in Delivering Continuing Teacher Education". American Journal of Distance Education, vol. 3, n. 2, pp 57-66, 1989.

CHAVEAU, P.: "The Electronic University of the Future". In: BARKER, J. \& TUCKER, R. (eds.): The Interactive Learning Revolution, Nichols Publishing, New York (E.U.A)., 1990.

CROOKS, B. \& KIRKWOOD, A.: "Video-Cassettes by Design in Open University Courses". Open Learning, Vol. 3, no. 3, pp 13-17, 1988.

EARL, A.W.: Design of a Telecourse: From Registration to Final Exam, Annual Conference on Emerging Technologies in Education and Training, Augusta, Maine, 29 Setembro 1989.

HARASIM, L.: "Online Education: A new Domain for Collaborative Learning and Communication". In: FEINSTEIN, B. \& KURSHAN, B. (eds.): 
Telecommunication in

Education: Learners and the Global Village, International Society for Technology in Education, Jerusalém (Israel), 1989.

HARRIS, D.: Openness and Closure in Distance Education. Falmer Press, U.K., 1987.

HEINICH, R.; MOLENDA, M.; RUSSEL, J.D.: Instructional Media and the New Technologies of Instruction. Macmillan Publishing Company, New York (E.U.A.), 1989.

HENRI, F. \& KAYE, A.: Le Savoir à Domicile: Pédagogie et Problematique de la Formation à Distance. Téléuniversité, Quebec (Canadá), 1985.

JOHN, M.: International Cooperation in Distance Education, trabalho apresentado no Distance Education Workshop, Harare (Zimbabwe), 9-11 Outubro 1991.

KOUL, B.N. \& JENKINS, J. (eds.): Distance Education: a Spectrum of Case Studies. Kogan Page, Londres, 1990.

LEMKE, R.A. et al.: Advancing Distance Education Programs with Ordinary Technologies, Proceedings of the Convention of the Association for Educational Communications and Technology (ERIC doc. ED 348 009), 1992.

MASON, R. \& KAYE, A. (eds.): Mindweave: Communication, Computers, and Distance Education. Pergamon Press, Londres (U.K.), 1989.

PERRY, W. \& RUMBLE, G.: A Short Guide to Distance Education. International Extension College, London, 1983.

PETERS, O.: "The Iceberg Has Not Melted: Further Reflections on The Concept of Industrialization and Distance Teaching". Open Learning, Vol. 4, no. 3, pp 3-8, 1989.

REZABEK, L.L et al.: Distance Education: Perspectives from All Sides of the Desk, trabalho apresentado ao Annual Meeting of the Association for Educational Communications and Technology, Washington, DC, 5-9 Fevereiro 1992.

RICHTIE, H. \& NEWBY, T.J.: "Classroom Lecture/Discussion vs. Live Televised Instruction: A Comparison of Effects on Student Performance, Attitude, and Interaction”. The American Journal of Distance Education, vol. 3, n. 3, pp 3645, 1989.

ROMISZOWSKI, A.J. \& HAAS, J.A.: "Computer-mediated Communication for Instruction: Using E-mail as a Seminar". Educational Technology, vol. 29, no. 10, pp. 7-14, 1989.

SAETTLER, P. : The Evolution of American Educational Technology. Libraries Unlimited, Inc., Englewood, Colorado, 1990.

THORPE, M.: Evaluating Open and Distance Learning. Longmans, Londres, U.K., 1988. 
ABSTRACT - The post-graduate Engineering programmes in Brazil have produced quite a number of new masters during the past few years. Only a small part of them, however, are employees specifically sent by their employers to obtain an advanced degree at the University. On the other hand, due to the economic recession, a good part of the master's candidates are young people that were not able to get a position in the job market. Most of them will be still wandering around the university after getting their master's diploma. Some will try a further doctor's programme. Others will seek a scholarship to study abroad, etc. This means that the impact of the Brazilian postgraduation programmes on the country's developing process has been not too significant.

In North America and in Europe distance education has been used extensively, even at the post-graduate level, with the clear objective of responding to the needs of the industry and society, and improving the skills of the labor force. This paper brings out, to the Brazilian audience, some conceptual and technical aspects related to distance education in Europe and North America. An up-dated bibliography will help the reader to further investigate the subject in more detail. An analysis of the perpectives and conditions to successfully introduce distance education in Brazil is presented.

Key-words: distance education, continuing education, engineering education. 